\title{
Infectious diseases in changing times
}

$\mathrm{H}$ EALTH CARE IN CANADA HAS UNDERGONE SUBSTANTIAL CHANGE over the past several years, and the process of change continues. A vision of the Canadian health care system of the future is cloudy, but it will certainly differ from today's. The primary force for change, resource limitation, operates not only directly in health care but also indirectly through changes in other programs. The most apparent changes to date are bed closures with downsizing of larger urban institutions. Occasionally, hospitals have been closed. This is part of the shift to community provision of health care from an institutional base. In addition, initiatives have variably decentralized or centralized services. Health care reform is cloaked in the semantics of 'health' and 'prevention', rather than a disease focus. The fundamental assumption underlying this philosophy, that fewer resources will be required to maintain the same outcomes is, of course, not supported by any available data. What about infectious diseases in Canada as we move through these changes? With increasingly limited resources and intense personal and institutional stress created by change, how do we limit the personal and social impact of infections in Canada?

Some issues are clear. First, new infectious diseases will continue to emerge (eg, hantavirus respiratory syndrome), and old infections will alter in epidemiology (eg, diphtheria in Russia) or virulence (group A streptococcus). Second, hospital acquired infections will remain an important cause of morbidity and mortality in any 'new' health care system. The shift to outpatient and short stay surgery may decrease some nosocomial surgical wound infections, but increases in patient acuity, continuing introduction of new technology, and more compromised patients will all increase the frequency and complexity of institutionally acquired infections.

Perhaps the greatest challenge of the upcoming decade will be problems of antimicrobial resistance. A vision of Streptococcus pneumoniae, Staphylococcus aureus, or tuberculosis infections untreatable with any antimicrobials is not apocalyptic, but is a logical extension of current epidemiological and scientific observations. Finally, our population remains vulnerable to infections acquired through environmental contamination, particularly of water and food systems. Resource limitations outside health care may have substantial impact here. For instance, over 400,000 cases of cryptosporidial diarrhea occurred in Milwaukee last year following contamination of the municipal water system. National and international transmission of infections to widespread, disparate populations through food distribution in a global food market has been repeatedly documented. Yet implications for in- fection transmission are seldom addressed when budget decisions are made, say, at the municipal level.

Certainly infectious diseases in Canada will remain a significant health concern. Current proposals for health care reform, if implemented, will not decrease these risks. In fact, limitations in resources, not just for health care but also for other programs, have the potential to facilitate infection transmission. In our global society, this may occur on a catastrophic scale. The lessons of the HIV epidemic of new disease emergence, global transmission, and therapeutic frustration must remain with us. Thus, as we progress through restructuring of our health care system, our continued vulnerability to infections must be acknowledged and potential risks actively identified. This is, of course, consistent with the philosophical approach of prevention rather than treatment, but may be in conflict with short term goals of budget restriction.

Our needs to meet the challenges are varied. A public health system providing excellence in management of communicable diseases is essential and must be a priority. This requires a supportive political milieu and effective interactions among all levels of government and between provinces. Vaccination programs must be promoted. Health care facilities must identify infection control and antimicrobial use programs as priorities and ensure the personnel developing and functioning in such programs are appropriately trained. Canadian systems to identify and transmit information describing infectious diseases including the national epidemiology of resistant organisms are essential. An integral component is the critical assessment of current and future programs to measure their effectiveness in Canadian health care. Optimal management of infectious diseases in our society will also continue to require promo tion of research at the basic science, clinical, epidemiological and health policy level. For all these activities, appropriately trained individuals are needed, and excellent Canadian training programs must be maintained. Finally, we must dissect out our own and others self-interests, and ensure the societal perspective remains our ultimate goal.

As we map our course through this period of health care reform, needs for prevention and management of infectious diseases will not change, but there will be increased challenges. Removing resources from programs related to control of infectious diseases, or restructuring of programs to meet doctrinaire rather than pragmatic targets without consideration of the impact on infection transmission in the Canadian population, is certainly a false economy.

LE Nicolle MDFRCPC Health Sciences Centre Winnipeg, Manitoba 


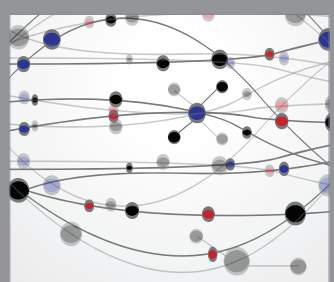

The Scientific World Journal
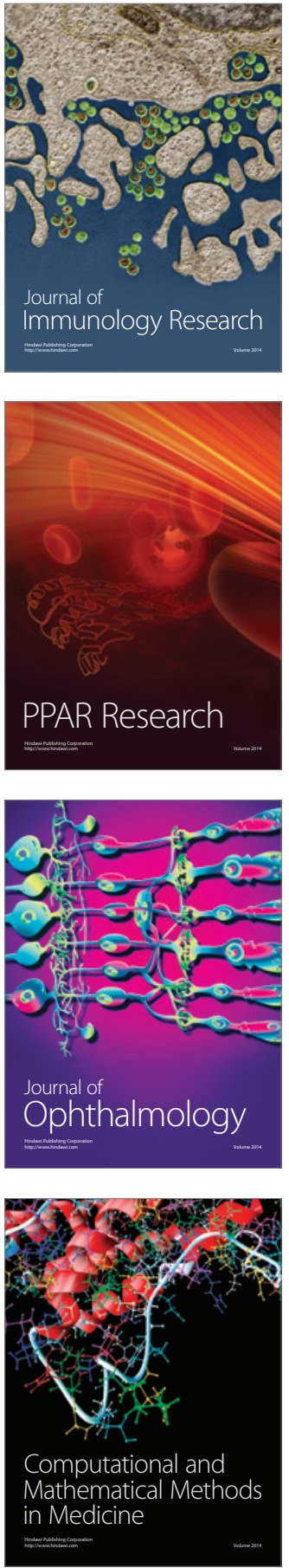

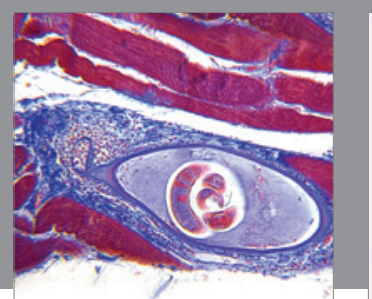

Gastroenterology Research and Practice

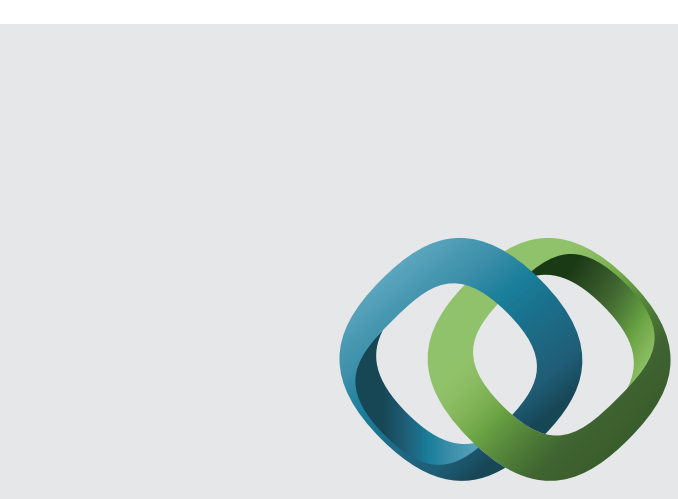

\section{Hindawi}

Submit your manuscripts at

http://www.hindawi.com
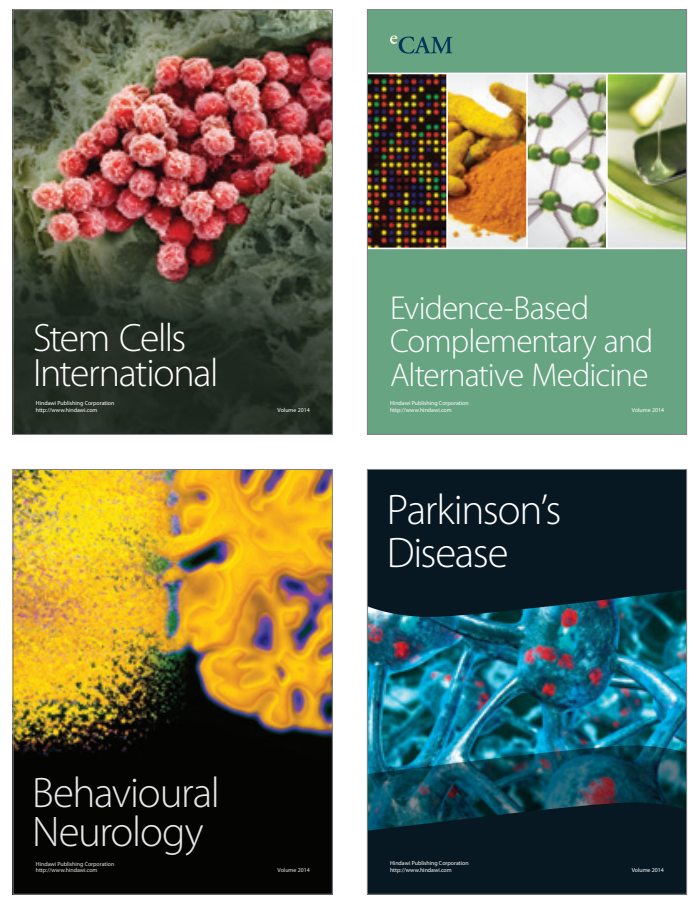
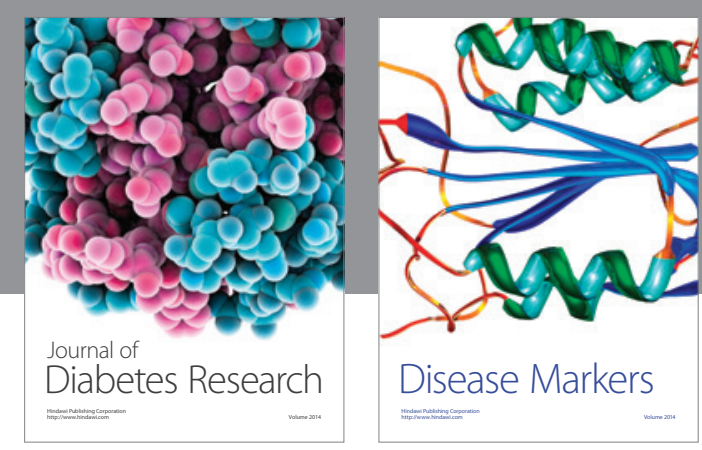

Disease Markers
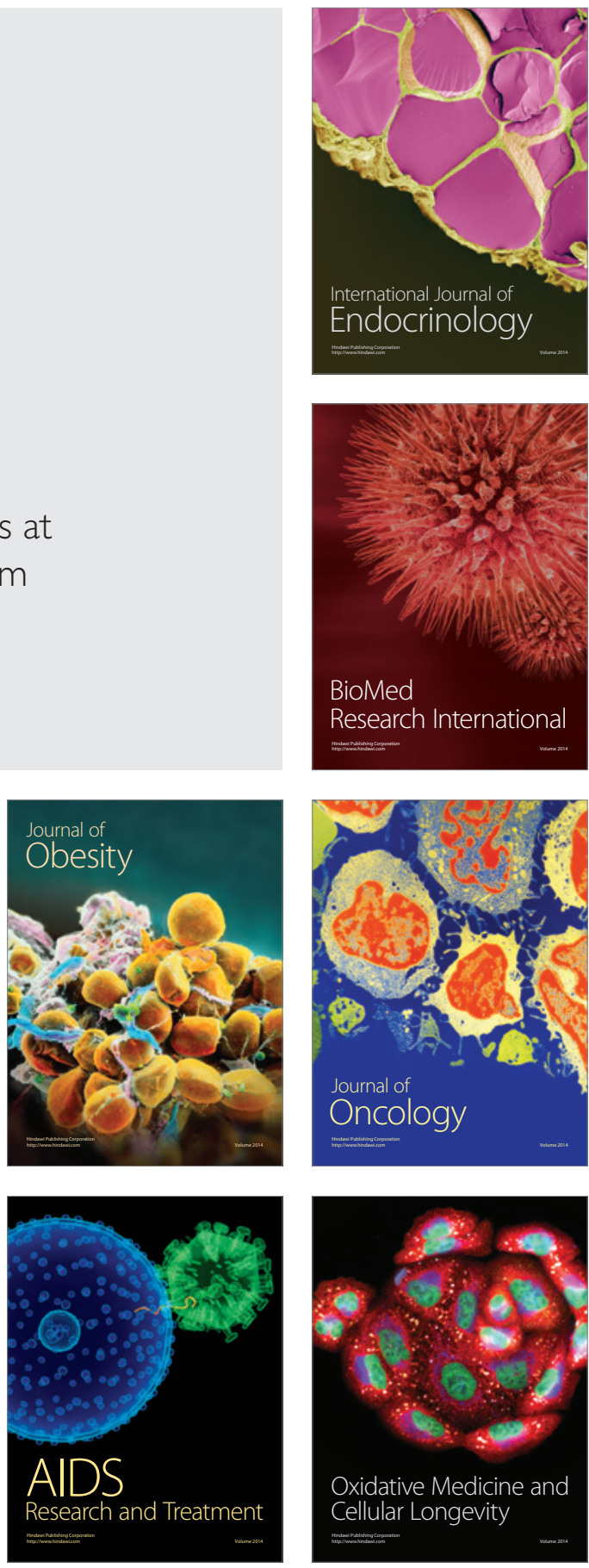